\title{
Avaliação do potencial biológico da Tabebuia aurea (Silva Manso) como fonte de moléculas bioativas para atividade antimicrobiana, antiedematogênica e antirradicalar
}

\author{
SANTOS, R.F.E.P.1; CONSERVA, L.M.'; BASTOS, M.L.A. ${ }^{* ;}$; CAMPESATTO, E.A. ${ }^{1}$ \\ 'Universidade Federal de Alagoas, Escola de Enfermagem e Farmácia. Campos A.C. Simões, Av. Lourival Melo \\ Mota, s/n, Tabuleiro dos Martins, Maceió - AL, CEP: 57072-900 *Autor para correspondência: lysetebastos@ \\ gmail.com
}

\begin{abstract}
RESUMO: As espécies da família Bignoniaceae e do gênero Tabebuia são amplamente utilizadas na medicina tradicional e possuem um forte potencial terapêutico. Diante disso, objetivou-se avaliar o potencial biológico da Tabebuia aurea, determinando a atividade antimicrobiana; por meio do método da microdiluição em caldo, para a determinação da Concentração Inibitória Mínima (CIM); antiedematogênica, pelo ensaio de edema de orelha induzido por capsaicina; e antirradicalar, frente ao radical DPPH. Os extratos etanólicos de $T$. aurea não evidenciaram citotoxicidade, exceto o extrato etanólico da flor nas concentrações $>0,5 \mathrm{mg} \mathrm{mL}^{-1}$. O extrato etanólico da flor foi ativo com ação bactericida frente a $S$. epidermidis (CIM de 0,06 mg mL-1) enquanto o extrato etanólico da folha foi moderadamente ativo frente a $S$. epidermidis (CIM: $0,25 \mathrm{mg} \mathrm{mL}^{-1}$ ) e $S$. aureus (CIM: $0,50 \mathrm{mg} \mathrm{mL}^{-1}$ ) sugerindo ação bacteriostática para ambas as linhagens. Os dois extratos apresentaram ação antiedematogênica, com inibição do edema de $40,50 \%$ pelo extrato etanólico da flor e de $41,73 \%$ pelo extrato da folha. T. aurea não apresentou atividade antirradicalar. Os resultados comprovam o perfil antibacteriano e antiedematogênico com ausência de citotoxidade pela $T$. aurea. Sugere-se a continuação dos testes com frações e substâncias isoladas das flores e folhas da referida espécie vegetal, bem como de experimentos in vivo, como forma de agregar evidências visando à busca de novos fitoterápicos.
\end{abstract}

Palavras-chave: Tabebuia aurea. Antimicrobianos. Viabilidade Celular.

\begin{abstract}
Biological potential assessment of Tabebuia aurea (Silva Manso) as a source of bioactive molecules for antimicrobial, antiedematogenic and antiradical activity. The species of Bignoniaceae family and genus Tabebuia are widely used in the traditional medicine and have a great therapeutic potential. The aim of the current research was to evaluate the biological potential of the Tabebuia aurea, determining its antimicrobial activity by the microdilution broth method, to predict the anti-edematogenic Minimum Inhibitory Concentration (MIC) by ear edema assay induced by capsaicin; and the antiradical one, towards DPPH. The ethanol extracts of $T$. aurea showed no cytotoxicity, except for the flower ethanol extract in concentrations above $>0.5 \mathrm{mg} \mathrm{mL}^{-1}$. The ethanol extract of the flower was active, with bactericidal action, against $S$. epidermidis (MIC $0.06 \mathrm{mg} \mathrm{ml}^{-1}$ ) and the ethanol extract of moderately active recto $S$. epidermidis (CIM: $0.25 \mathrm{mg} \mathrm{mL}^{-1}$ ) and $S$. aureus (MIC: $0.50 \mathrm{mg} \mathrm{mL}^{-1}$ ) were bacteriostatic for both strains. Both extracts had antiedematogenic action on the inhibition of edema of $40.50 \%$ by the ethanol extract of the flower and $41.73 \%$ by leaf extract. $T$. aurea did not show antiradical activity. The results indicate the antibacterial and antiedematogenic profile with no cytotoxicity by the $T$. aurea. It suggests the continuation of tests with isolated fractions and substances of flowers and leaves of that plant species as well as in vivo trials, in order to enhance the evidences targeted on finding new herbal medicines.
\end{abstract}

Keywords: Herbal Medicinal. Tabebuia aurea. Antimicrobials. Cell Viability. 


\section{INTRODUÇÃO}

Tabebuia aurea é uma espécie arbórea pertencente à família Bignoniaceae e ao gênero Tabebuia, comum na caatinga, bioma exclusivamente brasileiro, no Cerrado, Floresta Amazônica e Pantanal, sendo utilizada para fins ornamentais, medicinais, construção civil, entre outros (Lorenzi, 2002).

Os estudos sobre as atividades biológicas de $T$. aurea são escassos, porém esta espécie é usada popularmente como antiinflamatório, contra a gripe (Souza \& Felfili, 2006) e para picada de cobra (Reis et al., 2014). O extrato etanólico de suas hastes evidenciou atividade moluscicida contra Biomphalaria glabrata com concentrações letais médias (9-54 $\mu \mathrm{g} \mathrm{ml-1}$ ) bem abaixo do limite superior de $100 \mu \mathrm{g} \mathrm{ml}^{-1}$, estabelecido pela Organização Mundial de Saúde (Silva et al., 2007).

Estudos fitoquímicos com $T$. aurea isolaram flavonóides (Guerbas Neto, 2003) e terpenóides (Soares, 2006). Barbosa-Filho et al. (2004) isolou oito substâncias a partir das cascas do caule de $T$. aurea ( $\beta$-sitosterol; lapachol; os ácidos veratrico, betulínico e $p$-anísico; cinamato de metila e de (p-hidroxi)etila; 3,4',5-triidroxi-7metoxiflavona.

Estes compostos isolados das cascas de $T$. aurea evidenciaram um potencial antimicrobiano, por meio do teste de difusão em disco, contra Staphylococcus aureus, Enterococcus faecalis, Escherichia coli, Candida albicans e Monilia sitophila. Segundo Barbosa-Filho et al. (2004), estes resultados dão suporte aos usos medicinais tradicionais desta espécie.

Espécies do gênero Tabebuia têm sido usadas empiricamente como fonte de agentes antiinflamatório, antitumorais e antimicrobianos (Franco et al., 2013). Resultados de pesquisas básicas pré-clinicas desenvolvidas com este gênero evidenciaram o forte potencial antimicrobiano e antirradicalar, com ausência de citotoxicidade (Vasconcelos et al., 2014; Silva et al., 2014).

A literatura demonstra que espécies do gênero Tabebuia são amplamente utilizadas na medicina tradicional, e apresentam forte potencial terapêutico, o que se justifica a necessidade de avaliar o potencial biológico de Tabebuia aurea, determinando sua atividade antimicrobiana, antiedematogênica e antirradicalar, de partes como flores e folhas, as quais ainda não têm relato destas atividades.

\section{MATERIAL E MÉTODOS}

Foram coletadas $300 \mathrm{~g}$ das folhas e $300 \mathrm{~g}$ das flores da Tabebuia aurea (Silva Manso) Benth.
\& Hook. f. ex. S. Moore, conhecida popularmente como craibeira, ipê-amarelo ou "paratudo", em outubro de 2012, na Reserva Ecológica do Castanho, Delmiro Gouveia/AL, região do semiárido alagoano (Coordenadas geográficas: $9^{\circ}$ $26^{\prime} 20.5^{\prime \prime}$ S e $37^{\circ} 53^{\prime} 54.7^{\prime \prime}$ W). A identificação foi feita no Instituto do Meio Ambiente do Estado de Alagoas, onde uma exsicata encontra-se catalogada com o MAC $n^{\circ} 56122$.

A pesquisa foi aprovada com $n^{\circ}$ do processo 011/2014 pelo Comitê de Ética no Uso de Animais da Universidade Federal de Alagoas (CEUA/UFAL).

A secagem das folhas e flores foi realizada a sombra com ar circulante durante 60 dias. Depois de dessecadas, as amostras foram trituradas e submetidas à maceração a frio com álcool etílico a 97\%, de 72 em 72 horas. A cada filtração, a solução com extrato foi concentrada em evaporador rotativo a $40{ }^{\circ} \mathrm{C}$ e mantido em estufa banho-maria, para evaporação do solvente residual e obtenção do extrato etanólico.

\section{Ensaio de viabilidade celular}

Segundo a metodologia descrita por Lima et al. (2006), avaliou-se a viabilidade de macrófagos peritoneais de camundongos da linhagem Swiss, utilizando o Método Colorimétrico Metiltetrazolium (MTT), baseado na atividade das mitocôndrias pela redução do MTT.

As células foram plaqueadas ( $3 \times 10^{5} /$ por poço) e ficaram "over night", durante à noite, após foram expostas à diferentes concentrações dos extratos $\left(1.000,500,200\right.$ e $\left.100 \mu \mathrm{g} \mathrm{mL}^{-1}\right)$ por 48 horas. Os controles continham células com meio de cultura (Meio Dulbecco Modificado por Eagle DMEM) e com o diluente Dimetilsulfóxido. Após a incubação, foram adicionados $100 \mu \mathrm{L}$ da solução de MTT e as placas foram reincubadas (4 horas em estufa a $37^{\circ} \mathrm{C}$ e a $5 \%$ de $\mathrm{CO}_{2}$ ) e lidas em um leitor de microplacas $(530 \mathrm{~nm})$. Os resultados foram analisados pelo programa Graphpad Prism 5.0 ${ }^{\circledR}$ usando ANOVA, seguido do teste Dunnett, relacionado à lise. Os valores foram considerados significativos quando ${ }^{*} \mathrm{p}<0,05$.

\section{Microdiluição em Caldo}

Foram utilizadas linhagens padronizadas pela American Type Cell Cellection - ATCC/ Manassas - VA/USA. São elas: bactérias Grampositivas: Staphylococcus aureus (ATCC 25923), Staphylococcus epidermidis (ATCC 31488) e Enteroccocus faecalis (ATCC 29212); Gramnegativas: Pseudomonas aeruginosa (ATCC 27853), Escherichia coli (ATCC 25922), Klebisiella pneumoniae (ATCC 700603), Enterobacter

Rev. Bras. PI. Med., Campinas, v.17, n.4, supl. III, p.1159-1168, 2015. 
aerogenes (ATCC), Shigella flexneri (ATCC), Salmonella enterica (ATCC 1307), Acinetobacter calcoaceticus (ATCC 23055); e o fungo Candida albicans (ATCC 24433).

A atividade antimicrobiana foi determinada por meio da Concentração Inibitória Mínima (CIM), conforme o protocolo do Clinical and Laboratory Standards Institute (CLSI, 2012a). As amostras foram dissolvidas em Cremophor a $2 \%$, obtendo-se $20 \mathrm{mg} \mathrm{mL}^{-1}$.

Os inóculos foram preparados em Solução Salina Tamponada e a suspensão bacteriana foi determinada pela turvação do tubo 0,5 da escala de Mc Farland $\left(1,5 \times 10^{8}\right.$ UFC/ $\mathrm{mL}$ ), diluída numa proporção de $1: 10$, obtendose entre $5 \times 10^{5} \mathrm{UFC} / \mathrm{mL}$ e $5 \times 10^{4} \mathrm{UFC} /$ poço. A suspensão fúngica, também determinada pelo tubo 0,5 de Mc Farland ( $1-5 \times 10^{6} \mathrm{UFC} / \mathrm{mL}$ ), foi diluída 1:50 para se conseguir 0,5 a $2,5 \times 10^{3}$ UFC/mL (CLSI, 2012b).

A CIM foi realizada em microplacas de poliestireno de 96 poços. Todos os orifícios foram preenchidos com $100 \mu \mathrm{L}$ de caldo de cultivo Müeller-Hinton (MH). Nas colunas de 1 a 9 da linha $A, 100 \mu \mathrm{L}$ da solução das amostras foram inoculados, em triplicata, obtendo-se uma concentração de $10 \mathrm{mg} \mathrm{mL}^{-1}$. Em seguida, 100 $\mu \mathrm{L}$ da linha $A$ foi transferido para a $B$, e após homogeneização para a $C$, repetindo-se até a linha $\mathrm{H}$. Obtendo-se concentrações decrescentes em mg mL-1 de $10 ; 5 ; 2,5 ; 1,25 ; 0,62 ; 0,31 ; 0,15$ e 0,07 .

Posteriormente, foram adicionados $5 \mu \mathrm{L}$ de inóculo microbiano. Para o controle positivo utilizou-se o caldo de cultivo $\mathrm{MH}$ e o inóculo microbiano; o controle negativo avaliou a ação inibitória do diluente; e o controle de esterilidade, apenas o caldo $\mathrm{MH}$.

As placas foram incubadas em estufa bacteriológica a $35^{\circ} \mathrm{C}$ por 18 horas para as bactérias e por $28^{\circ} \mathrm{C}$ por $36 \mathrm{~h}$ para o fungo. Após este período, foram adicionados $20 \mu \mathrm{L}$ de Cloreto de Trifenil Tetrazólio (TTC) a 5\% (v/v), corante que promove a coloração das colônias sem comprometer sua viabilidade, e as placas foram reincubadas por mais 3 horas. A mudança de incolor para vermelho significou a presença de microrganismos e a ausência da coloração vermelha significou a ação inibitória do extrato sobre os microrganismos testados (Ayres et al., 2008; CLSI, 2012a).

A atividade antimicrobiana foi determinada de acordo com os seguintes critérios: CIM $\leq 1,0 \mathrm{mg} \mathrm{mL}^{-1}$ (ativa); $1,0<\mathrm{CMI} \leq 0,5 \mathrm{mg} \mathrm{mL}^{-1}$ (moderadamente ativa); 0,5< CMI $\leq 1,0 \mathrm{mg} \mathrm{mL}^{-1}$ (baixa atividade); e CIM $>1,0 \mathrm{mg} \mathrm{mL}^{-1}$ (inativos) (Ayres et al., 2008).

Uma alíquota das CIMs foram plaqueadas em meio Agar Mueller Hinton (AMH) ou Agar Sabouraud Dextrose (ADS), desprovido de microrganismo. Após 24 horas de incubação a $35^{\circ} \mathrm{C}$, para as bactérias, e a $28^{\circ} \mathrm{C}$ por 48 horas, para os fungos, considerou-se com ação bacteriostática o extrato que inibiu o crescimento do microrganismo na CIM, mas que houve crescimento na subcultura e ação bactericida o extrato que inibiu o crescimento na CIM e também na subcultura (Rocha et al., 2013).

\section{Avaliação da atividade antiedematogênica}

Foi realizado o ensaio de edema na orelha induzido por capsaicina em camundongos da linhagem Swiss, de acordo com Mantione \& Rodriguez (1990) modificado. Foram pesados $10 \mathrm{mg}$ das amostras e solubilizadas em 20 $\mu \mathrm{L}$ de Tween $80,980 \mu \mathrm{L}$ de acetona, ficando numa concentração de $0,1 \%$, administrados topicamente 40 minutos antes do estímulo flogístico induzido pela administração local na orelha direita de $20 \mu \mathrm{L}$ de capsaicina diluída em acetona (12,5 mg mL-1) (RAUH, 2008). Na orelha esquerda foi aplicado somente o veículo $(20 \mu \mathrm{L})$ utilizado para dissolução.

Os animais foram sacrificados 30 minutos após o estímulo flogístico e suas orelhas foram cortadas e pesadas, numa balança analítica, para obtenção do índice de inflamação. A porcentagem de inibição do edema foi determinada pela fórmula:

$$
\% \text { inflamação }=\frac{\text { Peso da orelha } D(\text { Tratada })-\text { Peso da orelha E (controle }) \times 100}{\text { Peso da orelha E (Controle })}
$$


Foram avaliados 4 grupos experimentais com $n=6$. No controle positivo foi avaliada a ação tópica da dexametasona (10 $\left.\mathrm{mg} \mathrm{mL}^{-1}\right)$, agente antiinflamatório, e no controle negativo apenas a capsaicina. Os resultados foram analisados pelo programa Graphpad Prism 5.0 ${ }^{\circledR}$, usando ANOVA seguido do teste de Bonferroni. Os valores foram considerados significativos quando ${ }^{*} p<0,05$.

\section{Avaliação da atividade antirradicalar}

De acordo com Soler-Rivas et al. (2000), realizaram-se os testes qualitativos e após a dissolução dos extratos em clorofórmio $\left(\mathrm{CHCl}_{3}\right)$, alíquotas $(2 \mu \mathrm{L})$ foram aplicadas em cromatoplacas 5 x 20 (sílica gel $60 \mathrm{~F}_{254}$, Merck), eluídas em solventes, e aplicou-se o controle positivo (+)-Catequina $(2 \mu \mathrm{L}$, $1 \mathrm{mg} \mathrm{mL}^{-1} \mathrm{em} \mathrm{CHCl}_{3}$ ). Em seguida, as cromatoplacas foram imersas, durante 10 segundos, em solução metanólica do radical sintético 2,2-difenil-1picrilidazila (DPPH) (Sigma, St. Louis, MO, EUA) a $0,4 \mathrm{mM}$ e secas. O surgimento de manchas amareladas sob um fundo roxo nos sugeriu uma possível capacidade sequestradora de radicais livres.

Posteriormente, foi determinada a curva de calibração do DPPH, por meio de uma solução estoque de DPPH metanólica $\left(40 \mu \mathrm{g} \mathrm{mL}^{-1} \sim 100 \mu \mathrm{Mol}\right.$ $\mathrm{L}^{-1}$ ) e foram feitas diluições seriadas de 40 a $1 \mu \mathrm{g}$ $\mathrm{mL}^{-1}$, submetidas à análise em espectrofotômentro UV/VIS, (SP-220 da Biospectro e UV mini-1240 Shimadzu®) a $515 \mathrm{~nm}$. Como controle positivo utilizou-se $\mathrm{MeOH}$ grau HPLC.

A curva foi construída a partir dos valores médios de absorbância de cada solução do DPPH versus as concentrações de 1 a $40 \mu \mathrm{g} \mathrm{mL}^{-1}$, por meio da análise de regressão linear utilizando o programa Microcal Origin Pro 8.0 (Figura 1). Esta análise forneceu a equação matemática da curva de calibração: $Y=A+B \cdot x$, no qual: $A=$ coeficiente linear; $B=$ coeficiente angular ou inclinação da reta; $\mathrm{x}=$ concentração de DPPH aos 60 minutos; com seu desvio padrão e coeficiente de correlação.

Os extratos etanólicos que forneceram resultados positivos nos testes qualitativos foram solubilizados em metanol $(\mathrm{MeOH})$ grau HPLC obtendo-se concentrações de 12,5 a $200 \mu \mathrm{g} \mathrm{mL}-1$ para a avaliação quantitaviva. Alíquotas de $0,1 \mathrm{~mL}$ dessas concentrações foram diluídas em $0,9 \mathrm{~mL}$ de solução metanólica do DPPH (100 $\left.\mu \mathrm{mol} \mathrm{L}^{-1}\right)$. Da mesma maneira as soluções estoques dos controles positivos padrões: Ácido Ascórbico e BHT (2,6-diterc-butil-4-metilfenol) foram preparados. A leitura da absorbância das concentrações, em triplicata, contra a solução de $\mathrm{MeOH}$ grau HPLC foi realizada em intervalo de 15 minutos em espectrofotômetro a $515 \mathrm{~nm}$. As absorbâncias das soluções foram registradas contra um branco ( $\mathrm{MeOH}$, grau HPLC).

A partir da equação matemática $Y=A+$ B.x e dos valores de absorbâncias obtidos pela média no tempo de 60 minutos, juntamente com os coeficientes angulares e lineares da reta da curva de calibração foi possível determinar à percentagem de DPPH remanescente (\% DPPH ${ }_{\text {REM }}$ ), conforme a fórmula:

$\% \mathrm{DPPH}_{\mathrm{REM}}=[\mathrm{DPPH}]_{\mathrm{T=t}} /[\mathrm{DPPH}]_{\mathrm{T}=0} \times 100$

Em que: $\% \mathrm{DPPH}_{\mathrm{REM}}=$ percentagem da concentração de DPPH que restou; $[\mathrm{DPPH}]_{\mathrm{T}=\mathrm{t}}=$ concentração de DPPH aos 60 minutos; e [(DPPH]

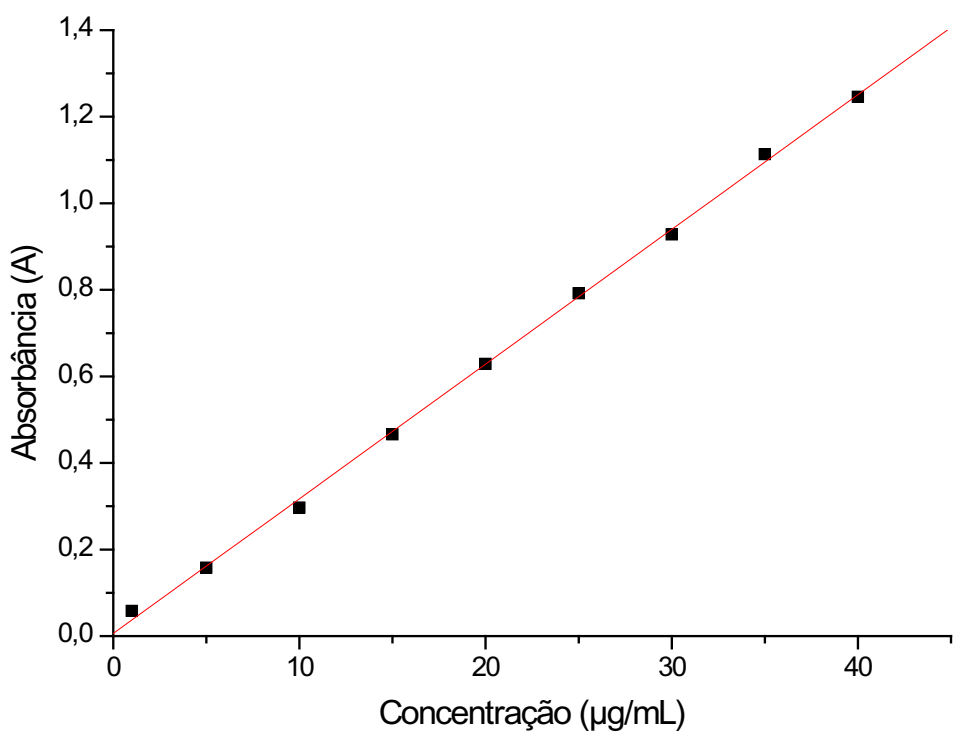

FIGURA 1. Curva de calibração construída a partir dos valores médios de absorbância de cada solução do DPPH versus as concentrações utilizadas (1 a $40 \mu \mathrm{g} \mathrm{mL-1).} \mathrm{Maceió/AL,} 2014$. 
TABELA 1. Concentração Letal de $50 \%\left(\mathrm{CL}_{50}\right)$ e citotoxidade máxima dos extratos etanólicos da flor e folha de T. aurea frente aos macrófagos peritoneais de camundongos da linhagem Swiss. Maceió/AL, 2014.

\begin{tabular}{lll}
\hline Parte da Planta & $\mathrm{CL}_{50}\left(\mathrm{mg} \mathrm{mL}^{-1}\right)^{\mathrm{a}}$ & Citotoxicidade máxima $(\%)^{\mathrm{b}}$ \\
\hline Flor & $0,565 \pm 0,055$ & $73,8 \pm 3,5$ \\
Folha & $>1,000$ & $\mathrm{NT}$ \\
Meio & $>1,000$ & $\mathrm{NT}$ \\
DMSO & $>1,000$ & NT \\
\hline
\end{tabular}

aConcentração Letal de $50 \%\left(\mathrm{CL}_{50}\right)$ calculada através de curvas concentração-resposta tóxica. 'Média \pm erro padrão da média (e.p.m) da citoxicidade máxima em triplicata. Os valores de efeito máximo foram considerados significativos quando ${ }^{*} p<0,05,{ }^{* *} p<0,01$ em relação ao grupo DMSO 0,1\%; NT: substância não que apresentou atividade letal significante para célula até a concentração de $1 \mathrm{mg} \mathrm{mL}^{-1}$ em relação ao grupo DMSO. Fonte: Autor, 2014.

$T_{T=0}=$ concentração de DPPH inicial $\left(40 \mathrm{mg} \mathrm{L}^{-1}\right)$. A curva das amostras foi construída relacionando a $\% \mathrm{DPPH}_{\mathrm{REM}}$ às concentrações avaliadas de cada extrato, por meio da análise de regressão linear utilizando o programa Microcal OriginPro 8.0.

A quantidade de antirradical necessária para reduzir a concentração inicial de DPPH em 50\% $\left(\mathrm{Cl}_{50}\right)$ foi obtida usando o modelo matemático $\mathrm{Y}=\mathrm{A}$ + B.x, na concentração de DPPH aos 60 minutos. Quanto maior o consumo de DPPH, menor será sua $\mathrm{Cl}_{50}$ e maior a sua capacidade de sequestrar radicais livres. Os extratos que apresentaram valores de $\mathrm{Cl}_{50} \leq 200 \mu \mathrm{g} \mathrm{mL}^{-1}$ devem ser indicados para continuação de estudos que venham reforçar a atividade antioxidante da $T$. aurea.

\section{RESULTADOS E DISCUSSÃO \\ Viabilidade Celular}

O extrato etanólico das folhas no ensaio da viabilidade celular não evidenciou citotoxidade, uma vez que a $\mathrm{CL}_{50}$ foi superior a concentração máxima utilizada $(1,0 \mathrm{mg} \mathrm{mL}-1)$. $O$ extrato etanólico não foi citotóxico nas concentrações $\leq 0,5 \mathrm{mg} \mathrm{mL}^{-1}$ (Tabela 1).

Conforme a Figura 2, não houve citotoxicidade estatisticamente significativa do extrato etanólico das folhas em todas as concentrações avaliadas e do extrato etanólico das flores nas concentrações de 0,2 e $0,1 \mathrm{mg} \mathrm{mL}^{-1}$. $\mathrm{Na}$ concentração de $1,0 \mathrm{mg} \mathrm{mL}^{-1}$ o extrato etanólico da flor apresentou citoxicidade elevada, semelhante à lise celular.

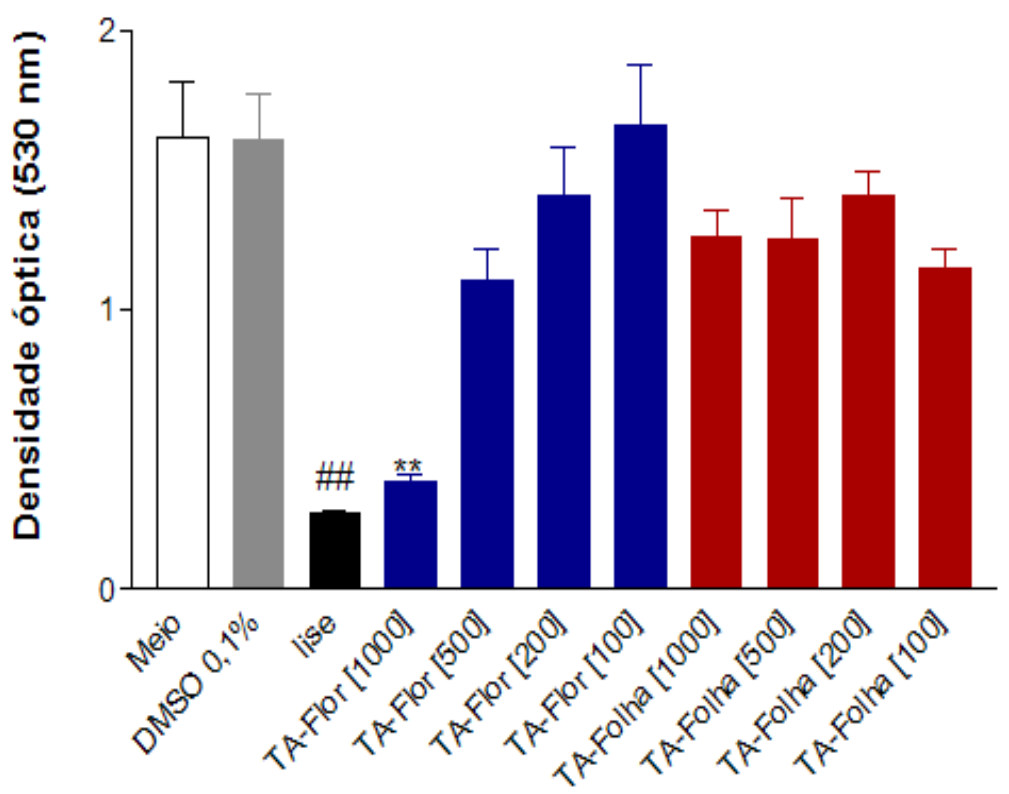

FIGURA 2. Viabilidade celular dos macrófagos peritoneais de camundongos da linhagem Swiss frente aos extratos etanólicos da flor e da folha de $T$. aurea nas concentrações 1,0; 0,5; 0,2 e 0,1 mg mL-1. Maceió/AL, 2014

Meio: DMEM; DMSO 0,1\%: diluente das amostras na concentração de 0,1\%; TA-Flor: Extrato etanólico da flor; TA-Folha: Extrato etanólico da folha. As colunas e as barras verticais representam a média \pm e.p.m., respectivamente, em triplicata. Os valores de efeito máximo foram considerados significativos quando ${ }^{*} p<0,05,{ }^{* *} p<0,01$ em relação ao grupo DMSO $0,1 \%$, usando ANOVA, seguido do teste de Dunnett.\#\#relacionado à lise. Fonte: Autor, 2014. 
Estudo evidenciou que os extratos etanólicos das folhas e das cascas do caule de T. impetiginosa apresentaram viabilidade celular pelo ensaio MTT, não induzindo citotoxicidade em macrófagos peritoneais de camundongos da linhagem Swiss nas concentrações $\leq 1 \mathrm{mg} \mathrm{mL}^{-1}$, o que sugeriu a continuação de estudos in vivo (Vasconcelos et al., 2014). As espécies T. serratifolia e T. stenocalyx não foram citotóxicas em concentrações $<0,5 \mathrm{mg} \mathrm{mL}^{-1}$ (Brandão et al., 2010).

A associação da avaliação da viabilidade celular de um composto à sua atividade biológica é fundamental para determinar sua aplicação, bem como seu o índice terapêutico (Freshney, 2000). Os extratos da espécie de T. aurea não evidenciaram citotoxicidade significativa, exceto o extrato etanólico da flor, o qual se indica utilizá-lo em concentrações $\leq 0,5 \mathrm{mg} \mathrm{mL}^{-1}$, visto que nestas concentrações não se evidenciou citotoxicidade celular. Estes resultados representam indícios de segurança na utilização terapêutica da espécie vegetal nos testes pré-clínicos in vivo.

\section{Concentração Inibitória Mínima (CIM)}

A CIM foi avaliada de acordo com os critérios adotados por Ayres et al (2008). Verificou-se que os extratos etanólicos das flores e das folhas de $T$. aurea apresentaram os melhores resultados frente às bactérias Gram-positivas. O extrato etanólico da flor evidenciou-se ativo frente à linhagem de $S$. epidermidis, como uma CIM de 0,06 mg mL-1 (Figura 3). Já o extrato etanólico da folha foi considerado moderadamente ativo frente a esta mesma linhagem, com uma CIM de 0,25 $\mathrm{mg} \mathrm{mL}^{-1}$, e frente
TABELA 2. Concentração Inibitória Mínima (CIM) dos extratos etanólicos da flor e da folha de Tabebuia aurea frente aos microrganismos avaliados. Maceió/ AL, 2014.

\begin{tabular}{l|l|l}
\hline \multicolumn{3}{l}{ Concentração Inibitória Mínima - CIM (mg mL-1) } \\
\hline Microrganismo & Flor & Folha \\
\hline Gram-Positivas & \multicolumn{1}{l}{ (10,00 } & 0,50 \\
S. aureus & $0,06^{*}$ & 0,12 \\
S. epidermides & $>10,00$ & 10,00 \\
E. feacalis & $10,00^{*}$ & $10,00^{*}$ \\
Gram-Negativas & $10,00^{*}$ & $10,00^{*}$ \\
E. coli & $>10,00$ & $10,00^{*}$ \\
K. pneumoniae & $>10,00$ & 10,00 \\
A. calcoaceticus & 10,00 & 1,00 \\
E. aerogenes & 10,00 & 10,00 \\
S. flexneri &
\end{tabular}

'Concentrações bactericidas. Fonte: Autor, 2014.

à linhagem de $S$. aureus, como uma CIM de $0,5 \mathrm{mg}$ $\mathrm{mL}^{-1}$ (Tabela 2). Os extratos de Tabebuia aurea não evidenciaram ação contra o fungo $C$. albicans.

A CIM de 0,06 $\mathrm{mg} \mathrm{mL}^{-1}$ do extrato etanólico da flor apresentou ação bactericida frente às linhagens de $S$. epidermidis e frente às linhagens de E. coli e K. pneumoniae na CIM de $10 \mathrm{mg} \mathrm{mL}^{-1}$. O extrato etanólico da folha apresentou ação bactericida frente às linhagens de E. coli, K. pneumoniae e A. calcoaceticus, também na CIM de $10 \mathrm{mg} \mathrm{mL}^{-1}$ (Tabela 2). As demais linhagens que evidenciaram sensibilidade frente aos extratos avaliados na CIM

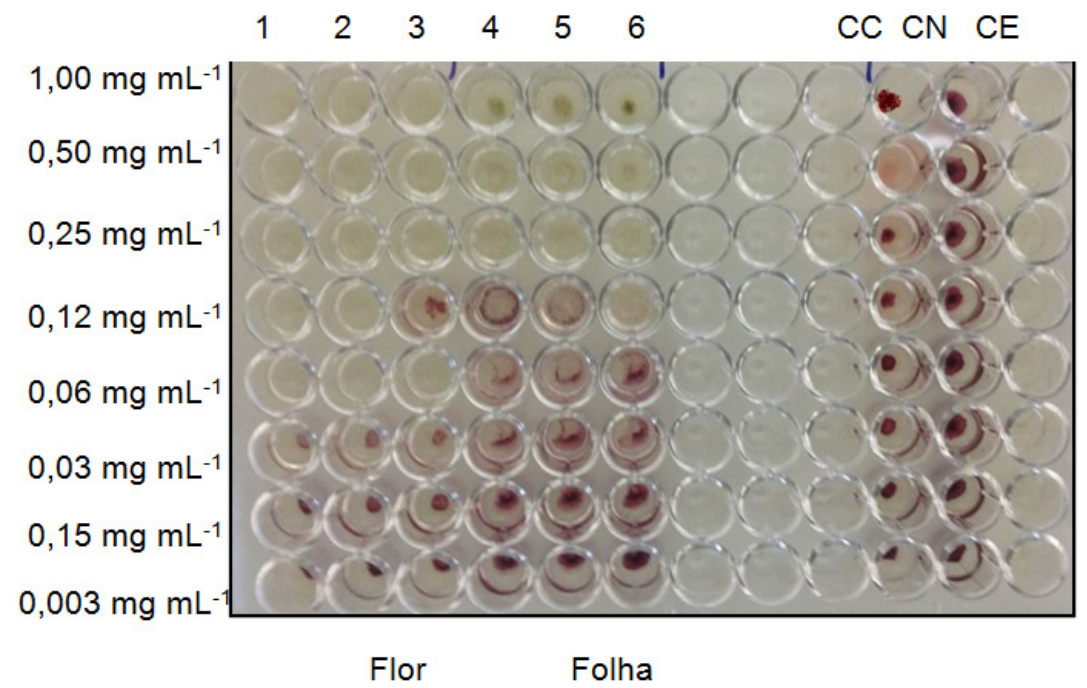

FIGURA 3. Teste de microdiluição em caldo evidenciando a Concentração Inibitória Mínima (CIM) dos extratos etanólicos da flor $\left(0,06 \mathrm{mg} \mathrm{mL}^{-1}\right)$ e da folha $\left(0,25 \mathrm{mg} \mathrm{mL}^{-1}\right)$ de $T$. aurea frente à linhagem bacteriana de Staphylococcus epidermides. Maceió/AL, 2014.

Triplicata 1, 2 e 3: Extrato etanólico da flor deT. aurea; Triplicata 4, 5 e 6: Extrato etanólico da folha deT. aurea; CN: Controle Negativo; CC: Controle de Crescimento; CE: Controle de esterilidade da placa. Fonte: Autor, 2014.

Rev. Bras. PI. Med., Campinas, v.17, n.4, supl. III, p.1159-1168, 2015. 
apresentaram ação bacteriostática.

Esta pesquisa evidenciou potencial antibacteriano de $T$. aurea frente à $S$. epidermidis, Quanto à ação sobre as demais bactérias, os extratos etanólicos de $T$. aurea necessitaram de CIMs mais elevadas para sensibilizá-las.

Aausência ou redução da ação bactericida de amostras vegetais frente a bactérias Gram-negativas tem sido observada por outros pesquisadores associadas às peculiaridades dos metabólitos secundários dos extratos, em formar complexos com proteínas solúveis extracelulares e parede celular, bem como, a característica lipofílica de alguns metabólitos, favorecendo a ruptura da membrana celular dos (Carelli et al., 2011).

Algumas pesquisas corroboram com esta ação reduzida sobre os microrganismos Gramnegativos demonstrando que outras espécies do gênero Tabebuia, como $T$. ochracea e $T$. rosea não apresentaram nenhuma ação contra as cepas de Escherichia colie Pseudomonas aeruginosa (Franco et al., 2013).

Entretanto, outro estudo evidenciou que o extrato etanólico da folha T. impetiginosa promoveu uma atividade antimicrobiana fraca contra as cepas Gram-positivas de S. epidermidis (CIM $\geq 0,62 \mathrm{mg}$ $\mathrm{mL}^{-1}$ ) e moderada para $S$. aureus (CIM $\geq 0,31 \mathrm{mg}$ $\mathrm{mL}^{-1}$ ) (Vasconcelos et al., 2014). Outra pesquisa demonstrou moderada atividade antimicrobiana de T. roseo-alba frente a três bactérias Gram-positivas: S. aureus, S. epidermidis, E. feacalis; e uma Gramnegativa: K. pneumoniae (Silva et al., 2014).

Diante disso, esta ação antimicrobiana reduzida ou mesmo ausente pode ser justificada, por se tratar de extratos brutos e a presença de seus fitocomponentes podem interferir na concentração da substância ativa. Ressalta-se então que os testes realizados com extratos brutos tendem a evidenciar resultados das CIMs mais elevadas e certamente seus compostos isolados devem apresentar uma atividade antimicrobiana maior (benfatti et al., 2010).

O ipê-roxo ( $T$. avellanedae), por exemplo, não apresentou atividade antimicrobiana in vitro (Suo, 2013). Entretanto, seus compostos isolados apresentaram promissora atividade antibacteriana frente às linhagens de estafilococos resistentes à meticilina, mas não foi observada atividade bactericida (MBC > 0,51 $\mathrm{mg} \mathrm{mL}^{-1}$ ) (Pereira et al., 2006).

O extrato etanólico das folhas da espécie $T$. pentaphylla Vell. apresentou atividade antibacteriana contra Enterococcus faecalis e Escherichia coli, com destaque frente à linhagem de $S$. aureus na concentração de $0,78 \mu \mathrm{g} \mathrm{ml}{ }^{-1}$, que também é bactericida (ROCHA et al., 2013). O Staphylococcus aureus foi à única estirpe sensível ao efeito de extratos e frações das espécies de $T$. ochracea e de T. rosea. Evidenciou-se a concentração crítica de $10 \mathrm{mg}$ poço-1 dos extratos brutos, enquanto que as frações de acetato de etilo de ambas as espécies exibiram uma forte atividade antibacteriana na concentração de $1,25 \mathrm{mg}$ poço-1 (Ospina et al., 2013).

Quanto à ação antifúngica, os extratos de T. aurea não evidenciaram ação contra ao fungo $C$. albicans. Porém, os compostos isolados das cascas do caule de $T$. aurea evidenciaram atividade inibitória frente à micobactéria e aos fungos Candida albicans e Monilia sitophila (Barbosa-Filho et al., 2004).

\section{Atividade antiedematogênica}

Os extratos etanólicos da flor e da folha inibiram a formação do edema quando comparado com o veículo, ou seja, evidenciam um perfil antiedematogênico, quando usados topicamente e na concentração de $0,1 \%$. O extrato etanólico da flor apresentou uma porcentagem de inibição do edema de $40,50 \pm 2,74 \%$ e o extrato etanólico da folha de $41,73 \pm 5,08 \%$, considerados estatisticamente significativos quando comparados ao veículo utilizado.

Os extratos etanólicos da folha e da flor diferiram significativamente $(\# p<0,05$ e \#\#< 0,01, respectivamente) do fármaco padrão utilizado. $\mathrm{O}$ Gráfico 3 evidencia que a dexametasona, fármaco

FIGURA 4. Porcentagem de inibição do edema de orelha induzido por capsaicina promovida pelos extratos etanólicos da flor e da folha de Tabebuia aurea. Maceió/AL, 2014.

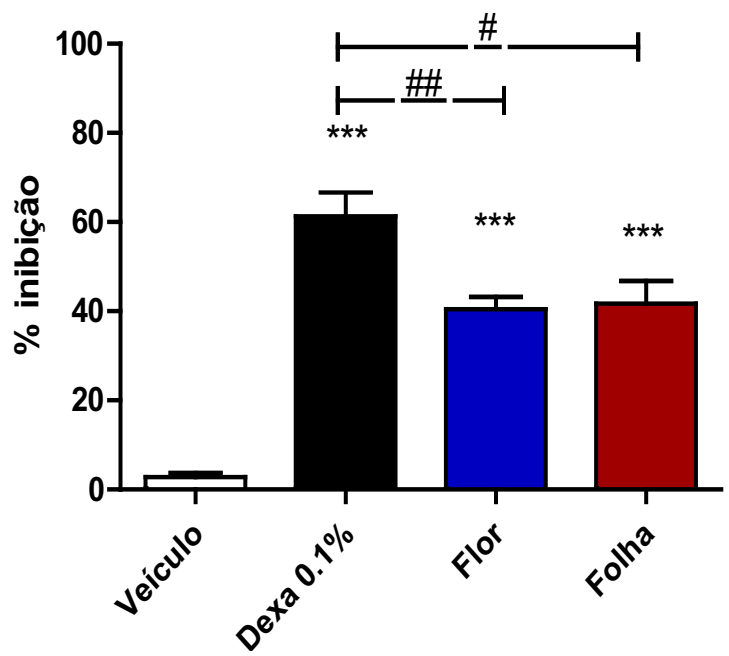

Veículo: Tween 80 , etanol e acetona na concentração de $0,1 \%$; Dexa 0,1\%: Dexametasona na concentração de 0,1\%; Flor: Extrato etanólico da flor de T. aurea. Folha: Extrato etanólico da folha de $T$. aurea. As colunas e as barras verticais representam a média \pm e.p.m., respectivamente $(n=6)$. Os valores máximos foram considerados significativos quando *** $p<0,001$ comparado ao grupo veículo; $\# p<0,05$ e \#\#p<0,01, comparado ao grupo Dexa $0,1 \%$, ambos usando ANOVA seguido do teste de Bonferroni. Fonte: Autor, 2014 
padrão utilizado como controle positivo, apresentou atividade antiedematogênica tópica (inibição de $61,33 \pm 5,40 \%$ ).

Os extratos de Tabebuia chrysanta G. Nicholson apresentaram um efeito antiedematogênico significativo no edema de orelha induzido TPA, com níveis de inibição entre 20\% e 23\% (Ospina et al., 2011).

Os extratos de $T$. rosea e $T$. ochracea também evidenciaram uma atividade antiedematogênica que não diferiu estatisticamente do valor apresentado por indometacina usada como referência, sugerindo a presença de fortes metabolitos secundários. $\mathrm{O}$ extrato bruto de $T$. rósea apresentou quase metade do efeito antiedematogênico (38,6\%) observado para a indometacina $(59,7 \%)$, mas suas frações diclorometano $(50,1 \%)$ e acetato de etila $(44,4 \%)$ apresentam valores de inibição semelhantes à indometacina, sendo consideradas promissoras (Ospina et al., 2013).

Os resultados de Ospina et al (2013) corroboram com os da presente pesquisa uma vez que foram avaliados extratos brutos e estes demonstraram um perfil antiedematogênico, apresentando mais da metade do efeito antiedematogênico observado pela dexametasona, droga de referência utilizada na presente pesquisa..

A atividade antiinflamatória de plantas está estreitamente relacionada aos constituintes taninos, flavonóides, cumarinas, saponinas e terpenos. Estudos realizados com óleos essenciais obtidos de diferentes espécies vegetais demonstraram ser os terpenóides substâncias com ação antiinflamatória

(A)

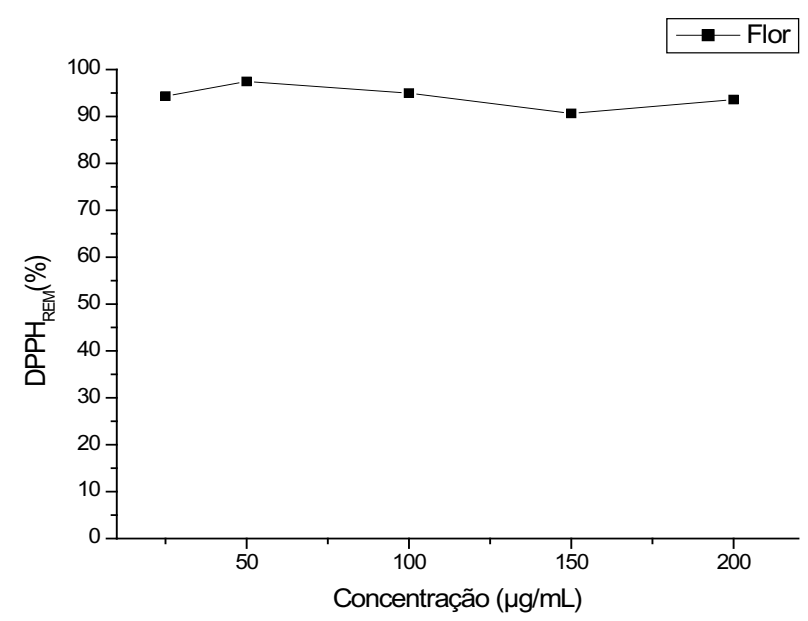

(Peana et al., 2004). Estudo das flores e folhas identificou a presença de terpenóides na $T$. aurea (Soares, 2006)

\section{Atividade antirradicalar}

Os dois extratos etanólicos da flor e da folha de $T$. aurea apresentaram resultados positivos nos ensaios qualitativos e foram submetidas à avaliação quantitativa. Neste ensaio, os valores de $\mathrm{Cl}_{50}$ encontrados para as amostras testadas foram muito superiores a $200 \mu \mathrm{g} \mathrm{mL}^{-1}$, demonstrando ausência da capacidade sequestradora de radicais livres. O Figura 4 evidencia o quão é insignificante a redução do radical livre pelos extratos avaliados, $\mu \mathrm{g} \mathrm{mL}^{-1}$ ), quando comparados com os padrões utilizados: ácido gálico $\left(\mathrm{Cl}^{50} 20,53 \pm 1,34 \mu \mathrm{g} \mathrm{mL}{ }^{-1}\right)$ e $\mathrm{BHT}\left(\mathrm{Cl}{ }^{50}\right.$ $97,86 \pm 2,52 \mu \mathrm{g} \mathrm{mL}^{-1}$ ) (Figura 5).

Corroborando com os achados da presente pesquisa, as amostras das folhas, galhos e casca do caule de $T$. impetiginosa também evidenciaram resultados positivos nas avaliações qualitativas, porém nos testes quantitativos nenhuma amostra apresentou capacidade sequestradora de radicais livres (Vasconcelos et al., 2014). Extratos e frações da casca interna das espécies de $T$. ochracea e $T$. rosea apresentaram atividade sequestradora de radicais livres pelo mesmo método de mensuração da redução do radical sintético estável DPPH (Ospina et al., 2013).

Seis compostos glicosídeos fenilpropanóides foram identificados e isolados a partir de extratos aquosos da $T$. avellanedae e todos evidenciaram uma forte capacidade seqüestradora de radicais

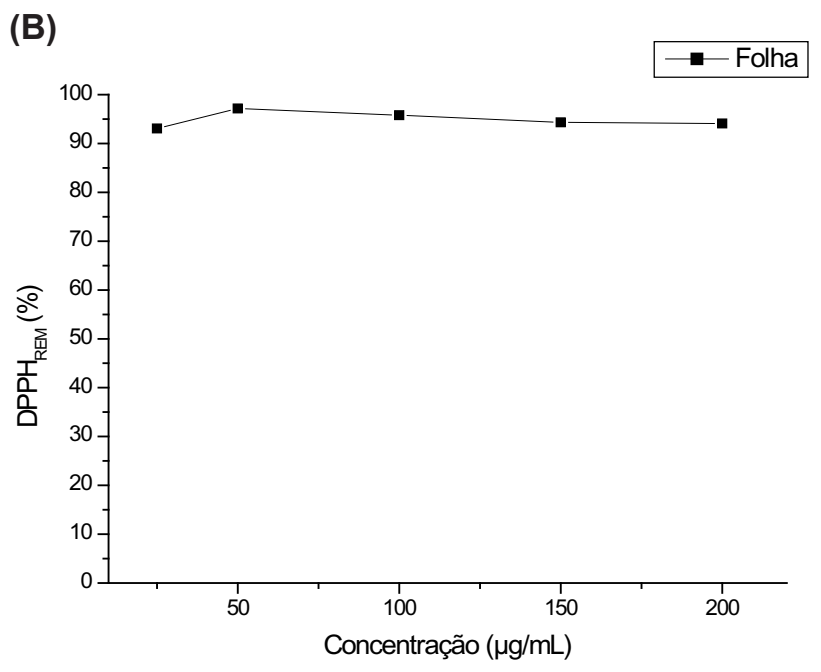

FIGURA 5. A) Curva da percentagem do radical livre sintético 2,2-difenil-1-picrilidazila (DPPH) remanescente frente ao extrato etanólico da flor de Tabebuia aurea. (B) Curva da percentagem do DPPH remanescente frente ao extrato etanólico da folha de T. aurea. Maceió/AL, 2014.

$\% \mathrm{DPPH}_{\mathrm{REM}}$ : percentagem da concentração de DPPH•(radical livre sintético) remanescente. Flor: Extrato etanólico da flor de T. aurea. Folha: Extrato etanólico da folha de T. aurea. Fonte: Autor, 2014.

Rev. Bras. PI. Med., Campinas, v.17, n.4, supl. III, p.1159-1168, 2015. 
FIGURA 6 - Cinética da percentagem do radical livre sintético DPPH remanescente dos padrões sequestradores de radicais livres: ácido gálico e 2,6-di-terc-butil-4-metilfenol (BHT). Maceió/AL, 2014.

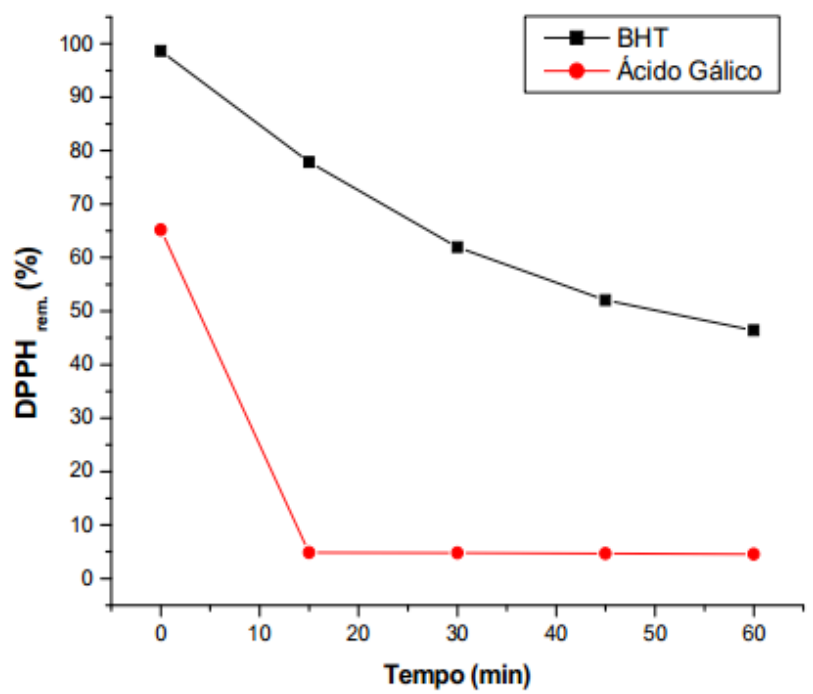

$\% \mathrm{DPPH}_{\mathrm{REM}}$ : percentagem da concentração de DPPH (radical livre sintético) remanescente; $\mathrm{BHT}$ (2,6-di-terc-butil-4-metilfenol) e Ácido gálico: controles positivos padrões sequestradores de radicais livres. Fonte: Autor, 2014.

livres no ensaio de DPPH (Suo et al., 2013). Outro estudo que investigou a atividade antioxidante de compostos isolados desta mesma espécie evidenciou uma fraca atividade antioxidante (Suo et al., 2012).

Os extratos etanólicos de $T$. aurea avaliados não evidenciaram atividade sequestradora de radicais livres. Entretanto, segundo Ospina et al. (2013) o fracionamento dos extratos totais das espécies de Tabebuia leva a um aumento significativo na atividade de eliminação de radicais livres de DPPH devido ao enriquecimento dos compostos ativos, com isso é relevante investir no fracionamento e particionamento dos extratos desta espécie.

\section{CONCLUSÃO}

No estudo da avaliação do potencial biológico da espécie Tabebuia aurea evidenciou-se o perfil antibacteriano e antiedematogênico, com ausência de citotoxicidade. No entanto, a atividade antirradicalar não foi evidenciada no presente estudo. A partir dos resultados obtidos sugere-se a continuação dos testes realizados com frações e substâncias isoladas das flores e folhas da referida espécie vegetal, bem como de experimentos in vivo, como forma de agregar evidências visando à busca de novos fitoterápicos.

\section{AGRADECIMENTOS}

Os autores agradecem o apoio financeiro do CNPq, CAPES e BNB.

\section{REFERÊNCIAS}

AYRES, M.C.C.; et al. Atividade antibacteriana de plantas úteis e constituintes químicos da raiz de Copernicia prunifera. Brazilian Journal of Pharmacognosy, v.18, n.1, p. 90-7. 2008.

BARBOSA-FILHO, J.M.; et al. Botanical study, phytochemistry and antimicrobial activity of Tabebuia aurea. Phyton, International Journal of Experimental Botany, v.73, p.221-28, 2004.

BENFATTI, C.S.; et al. Atividade antibacteriana in vitro de extratos brutos de espécies de Eugenia sp frente a cepas de molicutes. Revista Pan-Amazônica de Saúde, v.1, n.2, p.33-9, 2010.

BRANDÃO, G.C.; et al. Antiviral activities of plants occurring in the state of Minas Gerais, Brazil.Part 2.Screening Bignoniaceae species. Revista Brasileira de Farmacognosia, v.20, n.5, p.742-50, 2010.

CARELLI, G.; et al. Avaliação preliminar da atividade antimicrobiana do extrato de erva-mate (Ilexpara guariensis A. St. - Hil.) obtido por extração com $\mathrm{CO}_{2}$ supercrítico. Revista Brasileira de Plantas Medicinais, v.13, n.1, p.110-5, 2011.

CLSI. Clinical and Laboratory Standards Institute. Methods for Dilution Antimicrobial Susceptibility Tests for Bacteria That Grow Aerobically; Approved Standard. 3. ed. CLSI document M07-A9. Wayne, PA: Clinical and Laboratory Standards Institute; 2012a.

CLSI. Clinical and Laboratory Standards Institute. Performance Standards for Antimicrobial Susceptibility Testing. 22. ed. Informational Supplement. CLSI document M100-S22. Wayne, PA: Clinical and Laboratory Standards Institute; 2012b.

FRANCO, L.A.O.; et al. Antiinflammatory, antioxidant and antibacterial activity of two species of Tabebuia genus. Revista Cubana de Plantas Medicinales. v.18, n.1, p.34-6, 2013.

FRESHNEY, R.I. Culture of animal cells: a manual of basic technique. Wiley-Blackwell. 6. ed. 2000, 796p.

GUERBAS NETO, P. Estudo químico da casca, folhas e cerne de um espécime de Tabebuia aurea (Bignoniaceae) coletado no Pantanal. 2003. 120p. Dissertação (Mestrado em Química, Área de Concentração em Química Orgânica) - Universidade Federal de Mato Grosso do Sul, Campo Grande - MS.

LIMA, A.P.; et al. Avaliação da atividade antitumoral e citotóxica da Planta Siolmatra brasiliensis. Revista Eletrônica de Farmácia, v.3, n.2, p.44-6, 2006.

LORENZI, H. Árvores brasileiras: manual de identificação e cultivo de plantas arbóreas nativas do Brasil. 6. ed. Nova Odessa, SP: Instituto Plantarum, 2014, 384p.

MANTIONE, C.R.; RODRIGUEZ, R.A. Bradykinin (BK) - receptor antagonist blocks capsaicin-induced ear 
inflammation in mice. British Journal of Pharmacology, v.99, p.516-518, 1990.

OSPINA G., L.F.; et al. Anti-inflammatory and antioxidant activities of Phenax rugosus (POIR.) Wedd and Tabebuia chrysanta G. Nicholson. Vitae, Revista de la Facultad de Química Farmacéutica, v.18, n.1, p.49-55, 2011.

OSPINA, L.A.F.; et al. Actividad antiinflamatoria, antioxidante y antibacteriana de dos especies del género Tabebuia. Revista Cubana de Plantas Medicinales, v.18 n.1, 2013.

PEANA, A.T. et al. Effects of (-)-linalool in the acute hyperalgesia induced by carrageenan, L-glutamate and prostaglandin E2. European Journal of Pharmacology, v.497, n.3, p.279-84, 2004.

PEREIRA, P.M.; et al. Tabebuia avellanedae naphthoquinones: activity against methicillin-resistant staphylococcal strains, cytotoxic activity and in vivo dermal irritability analysis. Annals of Clinical Microbiology and Antimicrobials, v.5, n.5, 2006.

RAUH, L.K. Avaliação da atividade antiinflamatória tópica da Vernonias corpioides (Lam) persons em modelos de inflamação cutânea em camundongos. 2008. 119 p. Dissertação (Mestrado em Farmacologia) - Universidade Federal do Paraná, Curitiba - PN

REIS, FP. Tabebuia aurea decreases inflammatory, myotoxic and hemorrhagic activities induced by the venom of Bothrops neuwiedi. J. Ethnopharmacology, v.2, n.158, p.352-37, 2014.

ROCHA, E.A.L.S.S; et al. Potencial antimicrobiano de seis plantas do semiárido paraibano contra bactérias relacionadas à infecção endodôntica. Revista de Ciências Farmacêuticas Básica e Aplicada, v.34, n.3, p.351-355, 2013.
SILVA, J.C.; et al. Avaliação da atividade antimicrobiana de Tabebuia roseo-alba (Ridl.) Sand (Ipê branco). Revista Enfermagem Atual in Derme, v. 68, n. 6, p.08-11, 2014.

SILVA, T.M., et al. Molluscicidal activities of six species of Bignoniaceae from north-eastern Brazil, as measured against Biomphalaria glabrata under laboratory conditions. Annals of Tropical Medicine and Parasitology, v.101, p.359-365, 2007.

SOLER-RIVAS, C.; et al. Easy and fast test to compare total free radical scavenger capacity of food stuffs. Phytochemical Analysis, v.11, p.1-9, 2000.

SOARES, A.O. Estudo fitoquímico das flores e casca do caule de um espécime de tabebuia caraiba (bignoniaceae) coletado na região do cerrado em mato grosso do sul. 2006. 113p. Dissertação (Mestrado em Química, Área de Concentração em Química Orgânica). Universidade Federal de Mato Grosso do Sul- UFMS, Campo Grande- MS.

SOUZA, C.D; FELFILI, J.M. Uso de plantas medicinais na região do Alto do Paraíso de Goiás, GO, Brasil. Acta Botanica Brasilica, v.20, n. 1, p.135-142, 2006.

SUO, M.; et al. Anti-inflammatory constituents from Tabebuia avellanedae. Fitoterapia, v.83, p.1484-1488, 2012.

SUO, M.; et al. Bioactive Phenylpropanoid Glycosides from Tabebuia avellanedae. Molecules, v.18, p.73367345, 2013.

VASCONCELOS, C.M.; et al. Antimicrobial, antioxidant and cytotoxic activity of extracts of Tabebuia impetiginosa (Mart. ex DC.) Standl. Journal of Chemical and Pharmaceutical Research, v.6, n.7, p.2673-681, 2014.

Rev. Bras. PI. Med., Campinas, v.17, n.4, supl. III, p.1159-1168, 2015. 